\title{
O SER COM AIDS EM SUA DIMENSÃO EXISTENCIAL*
}

\author{
Dorotea Erica Dresler** \\ Magali Roseira Boemer***
}

\begin{abstract}
RESUMO: A inquietação sobre o significado de estar com AIDS, sob a perspectiva da pessoa que vivencia a doença, levou as autoras a uma pesquisa que as norteie para uma assistência de enfermagem que contemple o doente em sua dimensão existencial. Desta forma, utilizando os passos de uma investigação fenomenológica, puderam, a partir dos discursos das pessoas sobre as suas experiências vividas de um ser com AIDS, desvelar facetas que integram a essência desse vivenciar e que o afetam enquanto um ser histórico. O momento crítico de revelação do diagnóstico, o conviver com a doença e com os sintomas a ela inerentes, a perspectiva de finitude próxima, a configuração de seu horizonte existencial face ao que Ihes está acontecendo, foram facetas que emergiram e que são analisadas. Esses resultados contribuem, efetivamente, para uma assistência de enfermagem que assegure aos doentes 0 exercício de sua condição primordial de ser humano: a sua dimensão existencial.
\end{abstract}

\begin{abstract}
The uneasiness about the significance of having AIDS from the perspective of the person who experiences the disease led the authors to undertake a research that would guide them to provide nursing care based on an approach to the patient in his/her existential dimension. Thus, using the steps of a phenomenologic investigation and based on the discourse of the persons about their living experience of being a person with AIDS, the authors were able to discover facets which form the essence of this experience and which affect the persons as historical beings. The critical moment of the revelation of the diagnosis, living with the disease and its symptoms, the perspective of the approaching end, the configuration of their existential horizon in the presence of what is happening to them were facets that emerged and that were analyzed. These results effectively contribute to a type of nursing care that will garantee to the patients the exercise of their primordial condition as human beings: - their existential dimension.
\end{abstract}

\section{INTRODUÇÃO}

Nosso primeiro encontro acadêmico com a AIDS (Síndrome da Imunodeficiência Adquirida) aconteceu em junho de 1984 na II Jornada Brasileira de Enfermagcm em Doenças Transmissíveis e IV Encontro de Enfermagem em Doenças Transmissíveis, em São Paulo, evento que se constituiu num marco importante em nossa trajetória junto aos portadores de AIDS. Posteriormente, em setembro de 1985, pu- demos participar de um curso sobre AIDS no Hospital do Servidor Público em São Paulo, momento esse em que também ocorria a nossa indicação para enfermeira-chefe na Unidade de Moléstias Infecto-Contagiosas do Hospital das Clínicas, da Faculdade de Medicina, USP, local onde atuamos.

Iniciava-se assim, nosso caminhar em direção aos pacientcs portadores de AIDS, enquanto responsável pela assistência de enfermagem a eles prestada, já que, a partir de 1986, começavamos a atendê-los

* Prêmio Edith Magalhães Fraenkel - $1^{\circ}$ lugar - $44^{\circ}$ Congresso Brasileiro de Enfermagem - Brasília - DF. 4 a 9 de outubro de 1992

** Enfermeira-chefe da Clínica de Moléstias Infecção Contagiosas do Hospital das Clínicas da Faculdade de Medicina de Ribeirão preto-USP. Boslsista do CNPq - Programa de Aperfeiçoamento.

*** Professor Livre-docente da Escola de Enfermagem de Ribeirão Preto - USP. 
nessa unidade de internação.

A partir de então, gradativamente, começaram a surgir inquietações entre o pessoal de enfermagem, como preocupação com o tempo que permaneciam junto aos pacientes, com a distribuição em rodízio das coletas de sangue, com a situação em que a família rejeita o paciente. Elevou-se, também, o número de pedidos de licença-saúde e de acidentes de trabalho entre os funcionários da enfermagem.

Esses fatos nos preocuparam quanto à qualidade de assistência de enfermagem que estava sendo oferecida aos portadores de AIDS, face a um cotidiano de trabalho que se mostrava permeado por tensões. Buscamos, então, conhecimentos através de leituras de textos referentes à AIDS e participar de eventos que dela tratassem de alguma forma. Nossa primeira preocupação foi em relação às pessoas do serviço de enfermagem, que prestam cuidados aos pacientes.

Procuramos, então, um delineamento metodológico com uma docente da Escola de Enfermagem, e elaboramos um estudo que pudesse fornecer subsídios para as questões tão complexas, que envolvem a moléstia. Assim, realizamos uma investigação fenomenológica ${ }^{(12)}$. a fim de vislumbrar o significado do cuidar do paciente com AIDS, aos olhos do pessoal que presta cuidados nessa unidade de internação.

Nesse estudo, observamos as convergências nos depoimentos do pessoal de enfermagem, bem como, o rigor com que o cuidado é realizado, devido aos riscos de contaminação, permeado por um medo que está presente de forma clara, ou mais ou menos velada. Verificamos também, que as atividades de assistência de enfermagem estão ligadas ao desconforto físico, dada a especificidade das técnicas, tendo sido salientada a importância da opção pessoal para prestação desse cuidado.

A análise dos dados nos possibilitou verificar que o portador de AIDS, aos olhos do pessoal de enfermagem, se mostra como "difícil", é qualificado como inescrupuloso, agressivo, rebelde, carente, angustiado, deprimido, exigente e que não gosta de ficar sozinho.

Nesses momentos em que são expressos tais sentimentos, percebemos o quanto é difícil compreender o paciente, apesar de que, em geral, é possível vencer as barreiras e poder oferecer assistência de enfermagem com cuidado, carinho, conforto e uma palavra amiga.

Esse estudo ${ }^{(12)}$ nos remeteu a uma reflexão maior, com vista a compreender o lado ligado ao mundo do doente, de forma a melhor direcionar a assistência de enfermagem.

Para tanto, tornou-se para nós importante situar o mundo do doente, o horizonte de sua existência e como está percebendo o mundo ao seu redor, aos olhos de quem está vivenciando essa doença. Além do mais, no momento em que dois horizontes se encontram: o mundo do doente, e o mundo-vida do hospital, passamos a interrogar o significado da doença em sua existência e coexistência com os outros.

A partir dessas indagações, dispusemo-nos a prosseguir nossa pesquisa, buscando no presente estudo o significado, aos olhos do doente, de estar vivenciando a doença - AIDS. Revisamos, então, a literatura sobre a temática para buscar enfoques dos autores nessa perspectiva.

\subsection{Revisão da literatura}

Da consulta que vimos fazendo à literatura geral sobre a AIDS, temos visto que a doença tem sido bastante enfocada por autores das áreas médica, clínica, epidemiológica e que os autores em geral, vem se centrando nos aspectos fisiológicos, histopatológi$\cos$, imunológicos e de transmissibilidade, possibilitando, assim, um avanço do conhecimento científico imprescindível para o controle da moléstia. ${ }^{(1,5,19,29,30,32,33,36,37,40)}$

Autores como DURHAM e COHEN(14) consideram que a morte provoca fortes reações em alguns profissionais de saúde que trabalham com aidéticos. Este mal-estar é perpetuado por uma sociedade que usa de negação para lidar com a morte; relatam também que a epidemia da AIDS testa a capacidade da enfermagem de superar preconceitos e prevenções e proporcionar o melhor nível de tratamento possível às pessoas afetadas por esta doença.

DELUMEAU, ${ }^{(10)}$ em seu livro História do Medo no Ocidente, relata fatos dos anos de 1600 a 1700, por ocasião da peste negra, epidemia que devastou a Europa e gerou reações de toda a sociedade, fazendo com que o doente afetado pela peste fosse abandonado por pais, filhos, por todos. Era o tempo da "solidão forçada".

Encontramos no relato de KUBLER-ROSS ${ }^{(22)}$, que as pessoas esquecem que a maioria dos aidéticos - se não todos - morrem muito cedo, na época em que iniciam suas verdadeiras vidas, quando apenas começam a contribuir para a sociedade. A AIDS impõe sua própria ameaça para a humanidade; porém, diferentemente da guerra, a iniciativa da batalha contra ela 
tem que partir de dentro das pessoas, ignorando fronteiras ou divisas nacionais.

Há alguns autores que salientam as questões mais voltadas para a pessoa que tem a AIDS, como é o caso de $\operatorname{COSTA}^{(9)}$ e cols., que relatam uma experiência de grupo com pacientes HIV positivos, que teve como objetivo criar condições para os pacientes discutirem suas angústias, expectativas de vida, fantasias de morte e toda gama de sentimentos despertados a partir do diagnóstico. Referem que através desse trabalho em grupo foi possível ajudar os pacientes em vários de seus problemas.

Um estudo de caso, realizado por CORDAS, ${ }^{(8)}$ descreve o comportamento de um paciente com quadro esquizofrênico, ao suspeitar que estaria com AIDS. Paralelamente, lembra a pouca preocupação das campanhas sobre AIDS relativa ao lado psicológico do paciente.

SILVA, ${ }^{(39)}$ ao referir-se à assistência de enfermagem ao portador de AIDS, concluiu por considerá-la um desafio e recomenda a busca constante pela atualização de conhecimentos, de forma a melhorar a assistência de enfermagem. O stress vivenciado pela equipe de enfermagem é lembrado pela autora, acentuado pela falta de informações.

Em outro estudo sobre assistência de enfermagem a portadores de AIDS, relatado por Vieira ${ }^{(42)}$ e realizado em cinco hospitais do município de São Paulo, a autora cita vários problemas em relação à assistência, desde área física, desumanização e falta de treinamento, até a relação interpessoal. Verificou também que as expectativas do paciente, em relação ao atendimento de enfermagem, estão voltadas para a área expressiva, mas que os problemas relacionados a essa área não foram considerados relevantes pelos enfermeiros, que se mostraram mais preocupados com aspectos técnicos de sua atuação. Esse autor continua seu relato, dizendo que as vítimas da AIDS, na sua grande maioria, são abandonadas ou esquecidas pela família, ou pelos amigos e que a internação desses pacientes é tida como causadora de ansiedade entre a equipe de saúde, preocupados com sua segurança pessoal. Refere também, que há uma deficiencia qualitativa e quantitativa da assistência de enfermagem nos hospitais amostrados.

CASSORLA, ${ }^{(7)}$ supervisionando voluntáriamente uma equipe multiprofissional numa entidade que lida com doentes e portadores de AIDS, enfatiza a importância do grupo para ajudar os profissionais de saúde a enfrentar os problemas levantados junto aos doentes, como medo da exposição á doença, medo que a sociedade tenha conhecimento de seu trabalho junto aos aidéticos, além da ansiedade, medo da morte e o morrer e toda a gama de mecanismos mentais que invadem o profissional. Refere também que o paciente, sendo estigmatizado pela sociedade, caluniado e atacado por seu estilo de vida, muitas vezes já tem introjetada a responsabilidade por sua doença e pela epidemia. O que desencadeia a AIDS é a ação de um vírus e não o estilo de vida. Isso deve ser repetido centenas de vezes ao paciente e às vezes, o próprio profissional deve dizer isso a si mesmo.

Encontramos no relato de Mariotti, in BON$\mathrm{TEMPO}^{(4)}$, que a história da medicina mostra que uma doença não costuma atingir somente as pessoas que a contraem. A sociedade como um todo se ressente sempre das repercussões do sofrimento que a enfermidade produz, principalmente quando se refere às epidemias. No caso relativo à AIDS, essas repercussões têm sido de uma intensidade inédita.

Isso vem ocorrendo porque a AIDS tem a propriedade de atingir e solapar a dimensão mais básica do existente humano: o ser-para-o-outro ou, como diz HEIDEGGER, ${ }^{(17)}$ o ser-com; todos nós temos em comum a condição básica do homem de ser-no-mundo-com-os-outros.

Nas relações humanas temos a necessidade constante da confirmação por parte do outro, diz MARIOTTI, ${ }^{(24)}$ mesmo que em certos momentos essa possa ser negativa. Em outras palavras, o outro pode me amar ou me odiar e nisso está o imenso ligue de sentimentos entre os dois modos extremos de sercom. Porém, o que é difícil aceitar é que o outro simplesmente me ignore e isto me levaria ao não-ser, ao não-eu. A AIDS vem fazendo exatamente isso, pois, como se trata de uma doença transmissível e fatal ela provoca até o horror e o afastamento entre as pessoas.

Refere ainda esse autor que, embora já se tenha detectado o vírus da AIDS em vários dos fluidos do corpo humano, a evidencia clínica e experimental demostra que a transmissão se faz pelo contato sexual e pela transfusão de sangue ou derivados. Vida e morte se imbricam nesse estranho processo. Assim sendo, o outro, cujo papel é confimmar minha existência, passa a ser aquele que pode acabar com ela; pois, se o outro me passa a doença, estará me passando também o caminho para o não-ser-mais.

É necessário, portanto, entender - reconhece MARIOTTI $^{(24)}$ - que o portador de AIDS é um paciente em que o seu próprio ser-com está doente - é a existência humana em seu sentido mais profundo que está ameaçada. 
Quando caminhamos rumo à literatura na busca de conhecimentos pertinentes ao mundo do doente com AIDS, percebemos uma lacuna nessa perspectiva de abordagem, pois encontraremos mais ênfase sobre os fatores que abordam o lado do profissional de saúde e conhecimentos técnico-científicos sobre a doença. Portanto, consideramos que, desvelar a assistência de enfermagem, como ela vem se mostrando aos profissionais ${ }^{(12)}$ nos permitiu atentar para a relevância de, nesse momento, encaminharmo-nos para a faceta do doente que vivencia a doença - captá-lo e apreendê-lo em seu mundo e como interage com o mundo ao seu redor, como vê o seu horizonte de possibilidades em sua existência face à doença que contraiu.

Essa é a nossa proposta de estudo, prosseguindo na busca de clarear os caminhos envolvidos por essa moléstia.

\section{2 - REFERENCIAL TEÓRICO - METODOLÓGICO}

Para nos encaminharmos ao mundo do doente e compreendê-lo no vivenciar a sua doença - AIDS, buscando o que está se mostrando aos seus olhos, planejamos nossa pesquisa através da metodologia de investigação fenomenológica.

Esse homem, em seu sendo-doente-com-AIDS, necessita ser compreendido no seu mundo do qual a doença faz parte, ou seja, como ele se situa nesse mundo, como vê suas possibilidades, qual o significado da doença em sua existência para, então, poder ajudá-lo em seu conviver com essa situação de doença tão crítica.

Ante essa perspectiva, torna-se necessário explicitar algumas das idéias básicas da fenomenologia, de forma que o leitor possa fazer a leitura do presente estudo segundo este referencial.

\subsection{Idéias básicas da fenomenologia: algumas considerações}

A fenomenologia, enquanto movimento da filosofia, proposta por HUSSERL ${ }^{(18)}$ na primeira década deste século, representou o ensejo de um novo método para as ciências do homem que possibilitasse estudar esse homem em sua totalidade, em sua experiência vivida. Para esse filósofo, a ciência do vivido deveria ser construída a partir da "volta às coisas mesmas", da experiência consciente que se dá entre a pessoa e seu "mundo-vida" que significa presença no mundo antes da reflexão, a nível do vivido imediato (Lebenswelt).
Para HUSSERL, ${ }^{(18)}$ a pedra angular da filosofia baseia-se em que os fenômenos se revelam ao ser como dotados de uma essência. É na intersubjelividade que o mundo do ser e da ciência podem ser entendidos; essa é a sua contribuição para o compreender do Ser do homem.

Conforme bem expuseram NEVES(31) e SCATENA $^{(38)}$ a respeito do pensamento de HUSSERL, compreender aquilo que se manifesta em si mesmo na evidência do Ser, na sua experiência das coisas, é construir uma lógica segundo um referencial muito específico: o referencial do próprio Ser. Este é o cerne da fenomenologia: uma campo genuíno de dados possíveis - os fenômenos. Discriminar estes dados e esclarecê-los à luz de uma ciência rigorosa é a essência da fenomenologia.

O significado de fenômeno vem de expressão grega e deriva do verbo "fainestai". que quer dizer mostrar-se a si mesmo, significando, portanto, aquilo que pode tornar-se manifesto, visível em si mesmo. Só pode haver fenômeno enquanto houver sujeito no qual esse fenômeno se situa. Essa relação entre o fenômeno e o ser experienciador desvela uma consciência intencional. E a intencionalidade da consciência, segundo a qual, consciência é sempre consciência de alguma coisa, um "intentio" dirigido para um objeto, que é objeto para uma consciência,para a consciência que o visa e que lhe é capaz de discernir as essências.

Segundo NEVES ${ }^{(31)}$ a tarefa do pesquisador é chegar até a consciência e para tal é preciso debruçarse sobre essa busca. O sufixo "logia" da palavra fenomenologia deriva da palavra grega logos enquanto discurso; logos é um poder que a linguagem dá ao seu usuário, um recurso para compreender aquilo que se manifesta através da fala.

Assim, a fenomenologia significa discurso esclarecedor daquilo que se mostra por si mesmo. Ela será descritiva em seu modo de enfocar o fenômeno, partindo do cotidiano, da situação vivida, do vivido enquanto tal.

$\mathrm{Na}$ investigação fenomenológica o que se busca é a essência do fenômeno que pode se mostrar nos discursos dos sujeitos que o experienciam. Sob esse referencial, nossa proposta de compreender o doente com AIDS, só pode se concretizar se nos voltarmos para ele, procurando desvelar o que está significando, em essência, essa experiência aos seus olhos.

As suas descrições, as suas falas sobre o seu ver e perceber a doença, de como ela o afeta em sua 
existência nos possibilitam chegar à essência de seu viver e conviver com tal situação de dor.

\section{2 - O local e os sujeitos do estudo}

O estudo foi planejado para ser realizado junto aos doentes com AIDS que procurassem o H.C.F.M.R.P - USP., para internação ou para consulta, durante o período compreendido entre 21/02/91 e 21/10/91, nas duas Unidades de Internação de Moléstias Infecciosas deste Hospital (Campus e Unidade Emergência) e no Ambulatório de Saúde Pública. Nossa primeira preocupação, antes de nos achegarmos até ao doente, foi com relação ao seu diagnóstico, no sentido de nos assegurarmos de que o mesmo já fora revelado-lhe, considerando que essa revelação tem sido da competência médica, segundo o Códig de Ética Médica.

Outra preocupação esteve voltada para a privacidade necessária ao nosso encontro com o doente, co vistas a captá-lo em sua experiência e no seu significado em seu mundo existencial. No ambulatório procuramos por um local privado disponível e na enfermaria tal privacidade se deu naturalmente já que seu quarto é individual.

Achegávamo-nos, portanto, a cada doente, propondo-lhe falar sobre essa sua experiência de ser doente, colocando-nos enquanto pessoas que, embora conhecedoras de sua moléstia nos seus vários aspectos teóricos, de nossas vivências em prestar-lhe assistência, estávamos, sobretudo, inquietas em conhece a sua perspectiva, de quem vive a situação e pode nos revelar: "o que é isto, essa doença?".

Respeitando sua disponibilidade em nos ajudar, ouvíamos a sua fala, o seu dizer sobre como vê o qu está lhe acontecendo mediante a questão orientadora: Você conhece seu diagnóstico? Como está sendo ist para você?".

\subsection{Coleta de depoimentos}

Obtivemos então os seus discursos, os seus depoimentos em relação à questão orientadora durant esse encontro, essa entrevista, conduzida segundo a abordagem fenomenológica, a qual se dá sob a forma de existência situada no encontro.

"O encontro existencial não é programado. Ele é um fenômeno que se apresenta de maneira imprevista, ou seja, é um acontecimento com o qual me defronto e que vai exigir de mim um novo posicionamento. $\mathrm{O}$ encontro apresenta a alteridade radical d outro com o qual me deparo, me defronto e que me obriga a reconhecer que é uma realidade estranha a mim, que tem a sua identidade própria, fazendo-me, pois, apelo a meu descentramento de mim mesmo, indo, intencionalmente, à compreensão empática deste outro que aí está diante de mim."(6)

Segundo CARVALHO, ${ }^{(6)}$ ver e observar de uma perspectiva fenomenológica, é ver e observar a partir do tempo e do espaço do cliente. Vera partir do tempo do cliente é, portanto, captar a sua subjetividade, é poder tocar essa subjetividade no seu movimento existencial.

Os vinte depoimentos coletados segundo essa perspectiva metodológica podem ser esquematizados como se segue:

\begin{tabular}{c|c|c|c|c}
$\begin{array}{l}\text { Número de } \\
\text { Depoimentos }\end{array}$ & \multicolumn{2}{|c|}{ Sexo } & Idade & Local \\
\hline \multirow{2}{*}{20} & $\mathrm{~F}$ & $\mathrm{M}$ & Mínima =19 & Ambulatório = 11 \\
\cline { 2 - 5 } & 6 & 14 & Máxima = 46 & H.C. Campos =6 \\
\hline \multirow{2}{*}{} & & & & $\begin{array}{l}\text { Unidade de } \\
\text { Emergência = 3 }\end{array}$
\end{tabular}

Cabe salientar que não houve recusa por parte de nenhum paciente em fornecer o seu depoimento.

Após coletar cada depoimento procedíamos ao relato escrito do mesmo, tal como ocorrera. Nesses encontros pudemos observar que as condições clínicas dos pacientes inerentes à moléstia afetavam a forma de expressão de suas falas, possibilitando-se discursos mais extensos ou menos extensos. Paralelamente, a linguagem não verbal se tornava mais expressiva nos momentos de maior debilidade física. Nesse sentido, nos fundamentamos em BEAINI: ${ }^{(3)}$ "o ouvir e o silêncio são constitutivos do discurso".

\subsection{Leitura e análise dos depoimentos}

É através da leitura atentiva dos discursos dos sujeitos sobre o fenômeno que experienciam, que o pesquisador encontra os significados que são atribuídos por cada sujeito que vivência a experiência. Para essa análise os estudos de GIORGI ${ }^{(15)}$ e MARTINS $\&$ BICUDO $^{(25)}$ têm nos orientado. Esses autores sugerem quatro momentos para análise de discursos:

1- O pesquisador lê a descrição inteira, do início ao fim, sem buscar qualquer interpretação e tem uma noção do todo, procurando não ser um espectador, mas alguém que procura chegar aos significados atribuídos pelo sujeito da mesma forma como o sujeito o atribuiu. 
2- O pesquisador lê a descrição novamente, lentamente, ou quantas vezes achar necessário, identificando unidades de significado, focalizando o fenômeno que está sendo pesquisado. Esta leitura é como um "debruçar-se" sobre as descrições, perscrutando-lhe seu mundo-vida. Uma unidade de significado para MARTINS \& BICUDO ${ }^{(25)}$ é, em geral, uma parte da descrição cujas frases relacionam-se umas às outras.

3- O pesquisador percorre todas as unidades identificadas e expressa o significado contido nelas.

4- O pesquisador sintetiza as unidades de significados para chegará estrutura do fenômeno, à sua essência. Nessa síntese, o pesquisador integra os "insights" contidos nas unidades de significado transformadas em uma descrição consistente da estrutura situada no fenômeno.

\section{APRESENTAÇÃO E ANÁLISE DOS RESULTADOS}

Os depoimentos, em número de vinte, foram lidos atentivamente para que pudéssemos apreender o sentido no seu todo. As unidades de significado, que emergiram desses discursos, possibilitaram-nos apreender facetas pertinentes à sua existencialidade, enquanto ser um ser-com-AIDS:

1 - Como percebe a sua doença.

2 - O momento crítico de revelação do diagnóstico.

3 - O seu conviver com a doença.

4 - Seu horizonte existencial face à doença.

5 - A perspectiva da terminalidade.

\subsection{Como percebe a doença}

A questão orientadora, "como está vendo o que está lhe acontecendo?" nos permitiu observar que os doentes expressam o seu ver, verbalizando os sentimentos com que cada um vem percebendo a moléstia. Assim, houve discursos onde o medo está presente, em outros a perspectiva de morte ou ainda a fase da doença. Cada um pôde falar sobre sua maior inquietação face ao que está lhe ocorrendo.

Observamos também que as falas expressam um ser que fala de sua realidade concreta, ou seja, de um cotidiano impregnado pela realidade da doença. Chama-nos atenção a forma pela qual se referem à AIDS, evitando cautelosamente pronunciar o seu nome e para tanto, recorrem aos mais variados pronomes, muito presentes em seus discursos:

- Não tenho tanto medo "dela" em si, tenho medo da queda da resistência que "ela" proporciona.

- Não seria tão terrível, se "ela" não fosse uma doença visível.. "Ela" assusta... "ela" é monstruosa.

- "Isso" vai me levará morte.

- Procuro nem pensar que estou com "isso".

- "Ela" me ataca.

- Jamais esperava que "isso" fosse acontecer.

- Horrível, mas "isso" eu nunca esperei, nunca imaginei que fosse "isso".

Percebe-se que o doente, ao usar os pronomes "isso", "ela", "dela" espera que o interlocutor saiba o que ele quer dizer, parecendo sugerir que as complete silenciosamente. MENDES ${ }^{(28)}$. em estudo sobre o ser hanseniano, já observara esse recurso utilizado pelos hansenianos, evitando nominar sua doença.

Essas observações evidenciam um vivenciar oculto em que a mensagem, explicitando o termo AIDS, poderia levar mais claramente a uma interpretação de um ser estigmatizado pela sociedade, onde falar em AIDS acarreta o pânico, o medo, levando a alterações significativas das interações interpessoais, conforme já desvelamos em estudo anterior ${ }^{(12)} \mathrm{O}$ que se evidencia, portanto, nessas observações é que a essência da problemática que envolve a AIDS transcende a simples referência ao seu nome.

No nosso cotidiano de trabalho, percebemos também que a cautela na referência ao termo AIDS tem sido adotada entre os profissionais de saúde e, particularmente, da enfermagem quando ao nomear o doente com AIDS, usam expressões como "portador de HIV positivo" ou, se é criança, dizem que ele é "sidinho" ou "sidinha"* , numa forma carinhosa, mas que propicia um certo velamento de diagnóstico.

Além das substituições da palavra AIDS por um pronome, encontramos também outras expressões que os doentes usam para dar ao termo AIDS a conotação de como a estão vivenciando. Geralmente são palavras únicas que possibilitam uma clara com-

Termo decorrente de SIDA, que significa "Síndrome de Imunodeficiência Adquirida". 
preensão de seus sentimentos e do quanto ela se diferencia de qualquer outra molestia:

- Horrível!

- Péssimo!

- Uma barra!

- A AIDS é diferente!

Há uma lacuna no sentido de que os profissionais de saúde venham a compreender o ser do paciente, enquanto um ser-com-AIDS e, nessa perspectiva, considerar o doente em toda a sua existência, o seu ser-no-mundo, esforçando-se para estar-com ele em seu sendo-doente.

Ser-com-o-doente, conforme refere OLIVIE$\mathrm{RI},{ }^{(34)}$ difere completamente de uma atitude paternal, significa "ver" algo com certa dimensão e de forma pessoal, subjetiva e que leva ao interpretar; e o "ver" fenomenológico conduz à descrição do que é dado na consciência como vivência, ou seja, saber o que se passa realmente na consciência do SER, naquele momento.

\section{2 - O momento crítico de revelação do diagnóstico}

A doença envolve a questão pertinente à importância do conhecimento da mesma pelo doente no sentido da sua transmissibilidade e da imprevisibilidade de sua trajetória, dado o conhecimento científico gerado até então sobre a duração da doença.

A informação a respeito do diagnóstico deve ser dada ao doente, em primeiro lugar conforme recomenda PASTERNAK, ${ }^{(35)}$ numa perspectiva honesta, não pessimista, mas franca, por ser um dever ético e moral, pois envolve uma doença potencialmente contagiosa. Após a informação é necessário entender como se sente o doente. O início e o conhecimento da doença se mostram com destaque em suas falas:

- Quando fiz exame, já sabia, pois usava drogas, usei a seringa de um amigo.

- No começo quando meu marido me contou foi muito difícil.

- No começo tive medo.

- Quando soube foi duro.

- No começo foi um baque.

- Uma péssima notícia.

- Não sei quando peguei, acho que foi com uso de drogas.

- Quando soube, foi uma barra; não é nada fácil, foi muito difícil, não sei como peguei.
- Colheram meu sangue, deu positivo.

Através desses discursos percebemos que eles revelam as possíveis causas pelas quais adquiriram a doença, como o uso de drogas, evidenciando histórias de vida que os levaram a essa situação, a essa realidade "dura", difícil, um "baque" permeada pelo medo, e interligada a um passado. Um passado que não pode ser mudado, mas que pode ser interpretado e compreendido de forma diferente, com vistas a possibilitar-lhe encarar o presente, onde o diagnóstico é uma realidade cruel, sob uma perspectiva de uma relação humana que lhe fortaleça para esse enfrentamento e lhe possibilite realizar projetos, tendo em vista essa sua realidade.

A nosso ver, é essa possibilidade humana de uma perspectiva futura, ainda que bastante delimitada, que lhe permitirá resguardara sua dimensão de Ser humano, de humanidade no seu sentido existencial.

Os discursos dos doentes nos revelam essa disposição em modificar o presente a partir de uma "ruptura" com os hábitos passados com o seu tendo sido:

- Desde que soube, não uso mais (a droga).

- Parei desde que soube (a droga).

O diário de um jovem aidético ${ }^{(13)}$ refere que para ele, a AIDS foi, antes de tudo, a experiência da solidão. Refere também, que viu jovens receberem a notícia de que seu teste era positivo, como uma condenação á morte e prossegue seu relato expressando que no interior de sua vida abriu-se um vasto parênteses, que é a doença, e que sua nova data de nascimento é a do dia em que descobriu ser portador de AIDS.

A experiência de solidão relatada por esse autor, percebemos também nos doentes de nosso estudo. Assim é que em suas falas, quando se referem ao início da doença como um momento crítico de sua trajetória, não verbalizam a figura de nenhum familiar, nenhum amigo que tenha estado presente, parecendo que o tempo é que vai ajudá-los a sair do impacto.

\subsection{O seu conviver com a doença}

A partir do momento em que o doente toma conhecimento de sua doença, percebemos em seus discursos, que ele não verbaliza a figura de alguém significante. Entretanto, durante a trajetória do seu adoecer, ele se constitui num ser que vivência uma doença e, nesse vivenciar, há um conviver que se mostra de várias formas, possibilitando o emergir da 
figura de um "outro", de alguém que lhe possibilita sua característica humana essencial de ser-no-mundo-com-o-outro, a partir da facticidade da moléstia que o acometeu.

O seu sendo-no-mundo e suas perspectivas de vir-a-ser se tornam presenças vivas em suas falas, a medida que ele percorre sua trajetória. Nesse conviver estão presentes todas as transformações que se dão em seu mundo e nas facetas desse mundo: o seu mundo de adaptação, de relação com seus semelhantes e de sua relação consigo mesmo. Para esses pacientes, esse momento de vivenciar a doença está requerendo que o profissional de saúde tenha um interagir com ele no qual seu diagnóstico seja encarado como "normal". Nesse momento de seu conviver, esse é seu pedido de ajuda. Vejamos algumas falas nesse sentido:

- Considero uma doença normal, como outra qualquer.

- Encaro normal como se tivesse uma gripe, um resfriado.

- Prá mim, é uma coisa normal.

- Nem penso, vivo a vida normal.

A compreensão desse apelo do doente, através do qual necessita considerar a sua doença como "normal, para ser aceito e compreendido em sua concreticidade, requer de todos os "outros", que de alguma forma estão com ele em seu sendo-doente, uma interrelação cuja base é a ajuda e sustentação.

Outros discursos apontam para um conviver no qual a sintomatologia da moléstia está presente:

- Judia muito da gente.

- Estou muito fraco.

- Tenho medo da queda de resistência que ela proporciona.

Nesse sentido, também revelam temor, face a uma sintomatologia clássica percebida por eles, o emagrecimento, que surge com muita força nessas falas. Ainda que seja a magreza "do outro" ela está presente e os assusta, pois está relacionada à sua própria imagem corporal e ao que lhes pode acontecer.

- Eu via os outros tão emagrecidos.

- Ver os outros tão magros.

- Eu vejo os outros muito magros.

Outros discursos revelam o conhecimento do doente do estágio de sua doença:
- Não estou com AIDS ainda.

- Só tenho o vírus, não estou com a doença.

- Meu exame só deu positivo.

- Estou no estágio IV.

Conviver com a doença, por outro lado, apresenta-se como algo que afeta profundamente o seu existir, que está presente no seu pensar e ameaça a sua existência:

- Eu não vivo uma experiência e sim uma verdade nua e crua.

- Comigo seria diferente.

- Não consigo deixar de pensar.

- Fico atormentado.

Desse modo, quando ele retrata a sua imagem corporal ou a imagem "do outro" que lhe possibilita antever o estágio de sua doença como uma realidade cruel a atormentá-lo, percebemos que a doença o afeta primordialmente num dos pilares de sua existência: o seu corpo. Corpo entendido à luz de MERLEAU PONTY ${ }^{(27)}$, enquanto corpo encarnado, no sentido de atuante, vivo, ou seja, aquele corpo que, sendo um corpo biofisiológico, torna-se humano, se humaniza e se concretiza no mundo.

A agressão a seu corpo o assusta pois, conforme refere MERLEAU PONTY, ${ }^{(27)}$ é a partir do corpo próprio, do "corpo vivido", que posso estar no "mundo" em relação com os outros e com as coisas; o corpo é o nosso "ancoradouro no mundo", ou ainda, "o nosso meio geral de ter um mundo"; o corpo exerce essa comunicação vital com o mundo que faz com que ele se torne presente como o local de onde começo a perceber esse mundo.

A análise do seu conviver com a doença ainda nos possibilitou ver que a família está presente e, assim, o seu mundo de relações é contemplado no emaranhado de suas vivências de ser-doente:

- Ter me deixado esta criança, tenho minha família.

- Tenho um filho adotivo, minha irmã e uma prima em casa.

- Tenho minha esposa, meus filhos, uma filha moça.

- Tenho meu filho.

- Tenho minha família que é mais importante, tenho filho.

- Tenho dois filhos saudáveis.

Cabe ressaltar que essa presença da família não pode ser entendida como algo necessariamente "junto 
de" ou que implique em ajuda, em compreensão, aceitação.

Suas verbalizações sobre a ausência das famílias se constituem, em última instância, numa forma de torná-las presente. Nesse sentido, o discurso heideggeriano é bastante esclarecedor, ao nos apontar as várias formas de estar-com, as várias formas de discurso, as várias possibilidades de ser-com. Mesmo estando só, o paciente e um ser-com. O ser-só é um modo deficiente do ser-com.

- A minha família sabe, briga muito comigo.

- Meus parentes me abandonaram.

- Meu pai saiu de casa.

HEIDEGGER $^{(16)}$ chama a atenção para o fato que, mesmo sem a presença do outro, o ser-no-mundo é um ser-com-os-outros, pois a fenomenologia postula o mundo da coexistência em termos de encontro dentro do mundo. Assim, mesmo com a família ausente, ele e um SER-COM. Em outros momentos, o doente se vê compelido a participar aos familiares seu conhecimento da doença evidenciando saber que a via sexual possibilita a transmissão:

- O pior foi explicar para minha mulher.

- Tenho uma garota e um filho, eles fizeram o exame e não deu nada.

O seu ser-com-a-família desvela uma faceta relevante de sua existência, pois quando relatam "tenho meu filho", "tenho minha família", nos parece que essa família está de certa forma ao seu lado, compartilha de sua doença nas várias formas de estar-com. As brigas referidas por eles expressam também um compartilhar ainda que de modo deficiente.

O conviver do ser-doente-com-AIDS, a partir de seus momentos iniciais, passa pelo enfrentamento com a família e, a seguir, segue essa trajetória em seu mundo, na forma de zelo para com os outros, pois tem conhecimento dos meios de transmissão e, assim, toda atitudes junto-com-os-demais. Um cuidado com o outro, no sentido heideggeriano de zelo, de solicitude, também emerge em seus depoimentos:

- Tenho a consciência de como conviver com as pessoas, sem os prejudicar.

- Uso o mesmo banheiro, quando tenho um machucado procuro secar com gaze, jogo no saco, fecho bem.

- Tenho uma sobrinha e posso prejudicá-la.

- Que era para me cuidar, não doar sangue.

De outra forma, mesmo assumindo posturas para evitara transmissão da doença, percebe o afastamento de seus amigos o qual justifica pelo preconceito, como se mostra em suas falas:

- "Ela" assusta, corrompe as pessoas, destrói o diaa-dia numa amizade ou convivência social.

- As pessoas têm muito preconceito... e vão se afastar.

- Deixar de ser sozinho é o mais importante.

- Pela indiferença, pelo afastamento dos amigos que não tenho.

- Houve afastamento dos amigos.

Desvelar essas facetas nos remete ao referencial de AUGRAS ${ }^{(2)}$, que diz que, todos os tropeços, os desencontros, os problemas de aceitação do outro como tal, passam a refletir a dificuldade intrínseca de superar a ambigüidade fundamental do ser para si e para os outros. Vemos também no relato de MAY et al. ${ }^{(26)}$, que o encontro com o ser de outra pessoa tem o poder de comover-nos profundamente e potencialmente pode desencadear um processo de ansiedade ou de prazer.

Segundo relato de DREUILHE ${ }^{(13)}$, a população saudável receia o contato com os aidéticos, que terão muito poucos aliados e que, muitas vezes, só poderão contar consigo mesmos; refere ainda que freqüentemente se faz um vazio em torno dele, não necessariamente devido ao medo irracional do contágio, mas por uma repulsa instintiva pelos seres atingidos pela desgraça.

Nas relações humanas, temos a necessidade constante da confirmação por parte do OUTRO, mesmo que em certos momentos isso possa ser negativo, conforme relata MARIOTTI in BONTEMPO ${ }^{(4)}$, e que o medo de ficar só é, provavelmente, a maior ansiedade de nossos tempos. Ninguém realmente quer ficar só, como também relata LOWEN. ${ }^{(23)}$

Esse ser que se situa aí, num agora não escolhido de sua vida, nos relata OLIVIERI ${ }^{(34)}$, também tem uma vontade de ter bem-estar e ser um ser sadio, que não vivência uma doença, o que é percebido nos discursos onde expressam um coexistir com esse conviver trágico:

- Agora estou me cuidando, porque não tem mais jeito, mas estou conformado.

- Hoje procuro nem pensar que estou com "isso".

- Procuro não me deixar levar.

- Já estou conformado... eu já nem penso mais.

- Tenho sempre pensamento positivo... de modo 
geral, eu nao penso que estou com AIDS.

- Procuro não esquentar, senão fica pior.

Desvelar esta faceta, ao nosso ver, foi muito importante, pois nos mostra uma forma bastante realista, encontrada pelo doente, para lidar com sua situação e que pode nos encaminhar para uma abordagem honesta, ética, permeada pela esperança, pois desejar e e ter esperança são os pontos de projeção do "cuidado", conforme OLIVIERI. ${ }^{(34)}$

Em outros depoimentos encontramos relatos que revelam a relevância da mão amiga, aquela que pode superar preconceitos:

- Eu acho que o mais importante mesmo é o carinho, o apoio, nem que seja de uma só pessoa... estar junto.

- Meus amigos me dão apoio.

- Meus amigos não me deixaram.

- Ninguém faz pouco de mim.

\subsection{Seu horizonte existencial face à doença}

Enquanto um ser temporal, os doentes em seu conviver com a AIDS começam a perceber que seu horizonte de possibilidades já não lhes apresenta em toda sua plenitude; suas possibilidades vão se reduzindo, desde os eventos mais simples do cotidiano, até a possibilidade maior que é a da continuidade de suas existências.

Nesse conviver fazem uma reflexão sobre as regiões de seu horizonte existencial, que abrangem o passado (tendo sido), o presente (sendo) e o futuro (vir a ser).

O tendo-sido se lhes apresenta como algo que eles não podem mudar e que, para os paciente deste estudo, por dizer respeito às suas histórias de vida, está muito interligado ao seu presente, ao que lhes está acontecendo.

O presente, o seu sendo-doente, lhes acarreta sofrimento e dor, conforme vimos evidenciando. Quanto ao seu vir a ser, que implica numa perspectiva futura, que remete à grande possibilidade humana de realizar projetos, é a dimensão de suas existências que se apresenta fundamentalmente afetada. Vejamos suas falas:

- "Isto" fez com que mudasse muita coisa na minha vida.

- Não vai ser a mesma coisa.

- Desde dezembro tudo mudou.
- Mudou tudo, toda minha vida.

Mudanças essas que o obrigam a adotar outro tipo de comportamento relacionado ao seu passado, com vistas ao futuro:

- Não uso mais drogas e nem sinto necessidade, não faço mais sexo.

- Não quero nunca mais (a droga).

- Vou procurar me alimentar bem.

- Desde que soube não uso mais (a droga).

- Já parei desde que soube (a droga).

- Não vou usar mais drogas.

- O médico disse que era para me cuidar, não ficar perto de outros doentes.

Podemos compreender essas falas à luz do conceito de horizonte existencial no entender de Biswanger, citado em AUGRAS ${ }^{(2)}$ :

"Na vivência individual, não existe a separação entre passado e presente. Interpenetram-se. A relação do presente individual com o passado não é em si determinada pelo passado, mas, pelo horizonte dentro do qual são experimentados ao mesmo tempo presente e passado. Nessa perspectiva, não é o passado que determina o presente, nem este o futuro. Ao contrário, é o sentido da trajetória do ser que modifica a significação do passado e do presente".

Desvelar essa faceta nos permitiu observar que o doente percebe um horizonte futural a fim de superar suas ansiedades e outros sintomas penosos e tem esperança, como se vê em suas falas:

- Espero que apareça um tratamento, qualquer coisa até "lá".

- Quero viver

- Na minha firma posso voltar...

- Tenho certeza "ela" tem cura... não importa o que vai ser.

- Vejo os outros muito magros e eu não quero ficar assim e nem numa cama.

- Quero estar em casa.

O que se mostra para nós é que, em nossa proposta de cuidar, podemos nos voltar para essa dimensão existencial e contemplá-la. Assim, podemos em nosso estar-com o doente discutir de forma aberta e realista essa configuração de seu horizonte existencial, envolvendo-o e sensibilizando-o para perceber que, enquanto humano, permanece possuidor desse horizonte, ainda que a doença possa tê-lo estreitado. 
No pensamento heideggeriano. ${ }^{(16)}$ pertence às possibilidades do homem o relacionamento verdadeiro e positivo do "eu" com o outro que não busca a dominação mútua, mas contribui na edificação do ser mais homem e cada um.

Há momento, entretanto, em que no seu vivenciar a doença, emerge e desesperança:

Antes eu tinha esperança, agora estou começando a perder...

É quando a profissional de saúde precisa estarão seu lado e compreender, pois, a esperança é que os sustenta através dos dias, das semanas ou dos meses de sofrimento, conforme nos lembra KUBLERROSS. ${ }^{(21)}$ Também CASSORLA. ${ }^{(7)}$ ao referir-se a essa questão, nos atenta para o fato de que o vírus ataca o sistema imunológico e, nesse sentido, a psicoinumologia já demonstrou que o desespero e a desesperança diminuem a resistência ao alterar o sistema imunológico já atingido pelo vírus da AIDS. Para a manutenção da esperança, esse autor nos lembra da necessidade de um vínculo forte, de confiança e de acolhimento que a equipe que cuida do paciente pode lhe proporcionar. Quando um paciente não verbaliza a esperança, geralmente é prenúncio de morte iminente, é o momento em que podemos estar-com ele em sua finitude.

\section{5 - A perspectiva da terminalidade}

A idéia de morte é presente de forma clara e intensa nas falas dos doentes deste estudo, verbalizando que sabem que vão morrer, que o momento da terminalidade não está distante:

- Mas "vai" mais cedo.

- Sei que "ela" vai me "levar".

- "Esta" vai até o "fim".

- Não tem mais "jeito".

- A AIDS não cura e a gente morre.

- Ontem parecia que ia morrer.

- Parece que eles vão morrer.

- É o fim da vida.

- Já estou conformado... todo mundo vai morrer.

- Tenho até vontade de morrer logo para acabar com isso.

A análise desses depoimentos nos remete à análise existencial do ser, conforme MAY, R. et al. ${ }^{(26)}$, pois o ser é parte inseparável do não-ser, ou seja, para compreender o que significa existir, necessitamos perceber o fato de que podemos não mais existir.

O ser-para-a morte de cada um de nós é crucial e é inalienável. A inalienabilidade da morte, o fato simples mas irresistível de que cada um deve morrer, de que a morte é a única potenciabilidade existencial que ninguém pode arrebatar ao homem constitui-se na verdade fundamental do significado do Ser, conforme STEINER. ${ }^{(41)}$ Sob essa ótica, o morrer não é um evento, é um fenômeno a ser compreendido existencialmente.

STEINER $^{(41)}$ sublinha, ao interpretar as idéias de Heidegger, o ponto crucial da existência: a possibilidade de ser depende e só faz sentido a respeito da impossibilidade de ser que é a morte. Uma não pode ser sem a outra. Assim, a morte é, na acepção mais ampla, um fenômeno de vida.

Essas idéias que acreditamos, podem se mostrar estranhas e, de certa forma complexas a nós, profissionais de saúde e enquanto tais, bastante compromissados com o assistir para a vida, carecem de reflexões de nossa parte, quando considerarmos nosso cuidado ao paciente com AIDS.

Sendo a AIDS uma doença que nesse momento se apresenta como fatal, essa fatalidade se mostra aos doentes como evidenciamos em suas falas. Ajudá-los a lidar com essa proximidade de finitude parece-nos ser um dos pontos cruciais da assistência a ser prestada. Fundamentalmente porque implica em lidarmos com nossas próprias idéias, sentimentos e vivências a respeito da morte.

O cuidado ao paciente com AIDS passa, necessariamente, por esta questão. Cuidar, segundo o pensamento heideggeriano, é sempre solicitude e preocupação e é o estado primordial de ser. Estar-com esses pacientes nos momentos de sua terminalidade constitue-se num grande desafio e numa grande angústia a nossa angústia diante da nossa própria morte.

É nas intersecções da dimensão existencial entre paciente e profissional que pode ocorrer a gênese de um cuidado que contemple esses pacientes naquilo que lhes confere sua humanidade - a sua dimensão existencial.

Aceitar a condição de ser-para-a-morte e lutar pela vida constitui-se na verdadeira coragem de ser, pois supõe o confronto constante com o desconhecido, que é o não ser que nos afeta de diferentes maneiras. ${ }^{(11)}$

Essas ponderações nos remetem à questão da dignidade e, nesse sentido, concordamos com CARVALHO ${ }^{(6)}$ que a dignidade humana desse ser doente 
é algo a ser vivenciado concretamente. Ela não é um alvo distante a ser tocado ou atingido. Ela é vivida por inteiro no ato de cuidar.

Observar a morte em paz de um ser humano faz-nos lembrar uma estrela cadente, segundo KUBLER-ROSS. ${ }^{(21)}$ É uma entre milhões de luzes do céu imenso que cintila, ainda por um breve momento para desaparecer para sempre na noite sem fim. Continua relatando, prestar assistência a um paciente que enfrenta a morte, é se conscientizar da singularidade de cada indivíduo neste oceano imenso da humanidade. É uma tomada de consciência de nosso limitado período de vida.

\section{CONSIDERAÇÕES FINAIS}

A análise fenomenológica sobre o significado de estar com AIDS, aos olhos do doente que vivência a doença e como ele está vendo o que está lhe acontecendo desvelou para as autoras destes estudo várias facetas.

Uma delas refere-se à denominação por pronomes feito pelo doente a se referir à sua doença, numa forma de a ocultar; expressam ainda que a AIDS lhes provoca sentimentos contidos numa palavra única como "horrível", "péssimo", "uma barra".

A doença implica também num momento crítico que é o da revelação do diagnóstico. Este momento permite o emergir de uma realidade cruel e difícil, permeada pelo medo e que diz respeito à sua história de vida. Em sua trajetória de ser um ser-com-AIDS, percebe-se que surge todo um processo de convívio com a doença, que envolve o exercício da sua condição essencial de humano - o seu ser-no-mundo-comos-outros. Assim é que, quando manifesta que sua doença é "normal", está requerendo implicitamente que o encarem como "normal", assegurando uma provável aceitação do "outro".

Ao se referir à sintomatologia da doença, principalmente ao emagrecimento, seja o "seu" ou o do "outro", e também ao estágio de sua doença, que o assusta e o atemoriza, afetando a sua imagem corporal, ele nos diz muito de seu interagir com as pessoas ao seu redor. Seguindo MERLEAU - PONTY, (27) deixando de ser visto como o receptáculo passivo de um mundo de coisas que o rodeia, o corpo exerce, pele sensível, a comunicação vital como mundo. A família do doente também emerge como uma parte essencial de seu mundo, seja de modo eficiente ou deficiente de solicitude para com ele.

Continuando a sua trajetória de ser um ser-com
AIDS, o doente nos revela um sentido de zelo para com o outro, tomando atitudes que evitem a transmissão da doença. Entretanto, ele percebe e verbaliza o afastamento de seus amigos, que é justificado por ele devido ao preconceito. Em outros momentos verbaliza a relevância de uma mão amiga.

Em seu conviver percebe-se a forma realista como vê a sua doença no sentido de encontrar meios para lidar com ela como: "não esquentar", "não pensar", "ter pensamento positivo".

A sua história de vida se expressa na sua trajetória de doença; o seu tendo-sido que se reflete nos momentos presentes, o seu sendo, que é permeado por medo, sofrimento, preconceito. A partir de então, começa a perceber um estreitamento em sua perspectiva futural, afetando suas possibilidades de realizar projetos.

O seu horizonte existencial, portanto, sob a perspectiva de um projeto futural, está permeado pela esperança e desesperança, num movimento ambíguo. A desesperança é um sinal de finitude, de ${ }^{(21)}$ que é a possibilidade do não mais ser. ${ }^{(17)}$

Temos observado junto aos doentes internados, que os objetos ao seu redor, assumem um significado especial, passando a fazer parte de seu mundo. Assim, alguns objetos como livros, rádios, às vezes televisão, constituem-se em algo de muito importante para esses pacientes. Os livros fundamentalmente são de fundo religioso ou de natureza filosófica do tipo "como ser otimista", "como ter esperança e pensamento positivo".

Esses objetos dizem respeito à uma faceta de seu mundo, o "UNWELT", pontuado por MAY et al. ${ }^{(26)}$ Para o paciente com AIDS, essa faceta de mundo, a dos "objetos" ao seu redor, parece ser bastante enfatizada, pois lhe confirma de certa forma, a sua existência.

Par ao profissional de saúde, permitir que objetos significativos sejam parte de seu mundo, como também conhecer e compreender a sua dimensão existencial de ser-com-AIDS, são fatores primordiais para uma proposta de assistência que contemple o estar-com-doente em seu mundo, em qualquer momento de sua trajetória.

Nosso estar-com-o-doente, contemplando o seu horizonte existencial, poderá se dar através de uma abordagem ética, honesta, de confiança e acolhimento, permeada pela esperança e pela mão amiga. A nosso ver essa proposta passa, necessariamente, pela disponibilidade de estabelecer vínculos. 
Possibilitar formas para o doente lidar com sua finitude, é também um dos pontos importantes da assistência de enfermagem a ser prestada, pois a gênese de um cuidado que o contemple em sua humanidade se dá nas intersecções da dimensão existencial entre paciente e profissional.

Pode-se dizer que a assistência ao paciente com AIDS e permeada por momentos plenos dessa dimensão existencial - momento pleno, no pensamento de
KIERKEGAARD, ${ }^{(20)}$ "e o instante em que uma pessoa percebe repentinamente o sentido que encerra para o presente, um acontecimento do passado ou do futuro. Sua plenitude consiste em que nunca se reduza a um simples ato intelectual: essa percepção do nosso alcance implica sempre a possibilidade e a necessidade de alguma decisão pessoal, alguma mudança em suas estruturas ou alguma nova orientação frente ao mundo e ao futuro".

\section{5 - REFERÊNCIAS BIBLIOGRÁFICAS}

1. ANDRADE, A.L. Rastreamento sorológíco para doenças infecciosas em Banco de Sangue como Indicador do Mobilidade Populacional, Rev. Saúde Pública, v. 23, n 1, p. 20-25, fev. 1989.

2. AUGRAS, M. O ser da compreensão. Petrópolis, Vozes, 1981.

3. BEAINI, T.C. A Escuta do silêncio. In: Estudo sobre linguagem no pensamento Heidegger, São Paulo: Cortez, 1981.

4. BONTEMPO, M. AIDS - Esclarecimento Global e uma abordagem alternativa, São Paulo: 158p.

5. BORDIN, J.O. \& CHIATTONE, CS. Infecção Pós-transfuncional pelo Vírus H.I.V. Rev. Paul. Med.. v. 106. n³, p. 118-125. mar/jun 1988.

6. CARVAlHO, A.S. Metodologia da entrevista - uma abordagem fenomenológica. Agir: Rio de Janeiro. 1987

7. CASSORLA. A.S. Da morte - estudos brasileiros. Campinas, S.P.: Papirus. 1991.

8. CORDAS. J.A. Reagudização do quadro esquizofrênico por pseudo-AIDS ou medo de AIDS. Rev. Paul. Med.. v. 104, $\mathrm{n}^{\circ} 2$, p. 111, mar/abr. 1986

9. COSTA, L.P.M., LIMA, CA. \& MELO FILMO, J. de "Grupo terapia com Paciente HIV Positivo (AIDS)" Inf. Psiqui., v.8. $\mathrm{n}^{\circ} 3$, p. $97-103$, jul/set. 1989.

10. DelumeaU, J. História do medo no Ocidente. São Paulo: Editora Schwarez Ltda. 1990. 471p.

11. DICHTCHKENIAN, M.F.S.F.B. Vida e morte - ensaios fenomenológicos. São Paulo: Companhia Ilimitada, 1988

12. DRESLER, D.E. \& BOEMER, M.R. "O significado do cuidar do Paciente com AIDS - uma Perspectiva de Compreensão" Rev. Bras. de Enf, v.44, n¹, p.70-81, jan/mar 1991

13. DREVILHE, A.E. Corpo a corpo - AIDS - diário de uma guerra. São Paulo: Paz e Terra, 1989.

14. DURHAM, J.D. \& COHEN, F.L. A Enfermagem e o Aidético. São Paulo: Manole, 1989, 277p.

15. GIORGI, A. Phenomenology and psychological research Pittsburg: Duehisne University Press, 1985

16. HEIDEGGER, M. Todos nós... ninguém - um enfoque fenomenológico do social, trad. de Dulce Mara Critelli. São Paulo: Moraes, 1981.

17. El ser y el tiempo. Tradução de J. Gaos. México: Fondo de cultura, econômia, 1986

18. HUSSERL A filosofia como ciência do rigor. Coimbra: Atlântida, 1965

19. ISHAK, R.; LINHARES, A.C. \& ISHAK, M.O. - Biossegurança no laboratório. Rev. Inst. Med. Trop., São Paulo, v. 31, no 2, p. 119-125, mar/abr. 1989.

20. KIERKEGAARD, S. In: MAY, R. et al. Existência. Nuevas dimensiones en psiquatria y psicologia. Madrid:Editorial Gredos, 1977, p.98.
21. KUBLER ROSS, E. Sobre a morte e o morrer. São Paulo: Martins Fontes, 1969.

22._ AIDS - O Desafio Final. São Paulo: Editora BestSeller, 1987.

23. LOWEN, A. O corpo em depressão, as bases biológicas da fé e realidade. São Paulo, Summer, 1972, 220p.

24. MARIOTTI, H. In: BONTEMPO, M. AIDS: esclarecimento global e uma abordagem. São Paulo: Alternativa. 158p.

25. MARTINS, F. \& BICUDO, M. A. Pesquisa Qualitativa em Psicologia - Fundamentos e Recursos Básicos, São Paulo: Moraes, 1989.

26. MAY. R. et al. Existência, Nuevas Dimensiones en psiquiatria y psicologia. Madrid: Editorial Gredos, 1977.

27. MEARLEAU - PONTY, M. Filosofia como corpo e existência. São Paulo: Escrita, 1992.

28. MENDES, I.J.M. O ser hanseniano, Ribeirão Preto. Tese (doutorado) - Escola de Enfermagem de Ribeirão Preto, 1991.

29. MENDES. N.F. Imunologia da AIDS. Rev. Paul.Med., v. 105, $\mathrm{n}^{\circ} 1$, p. 3, jan/fev 1987.

30. NETO, M. B. et al. Padrão Lesional da Medula Óssea na Imunodeficiência Adquirida (AIDS). Rev. Inst. Med. Trop., São Paulo, v. 30, n 4, p. 253-258, jul/ago. 1988.

31. NEVES, M.C.D. Uma perspectiva fenomenológica para o professor em sua expressão do: o que é isto, a ciência? Tese (doutorado) - Faculdade de Educação da Universidade Estadual de Campinas, 1991.

32. OLIVEIRA, J. S., PASTERNAK, S., FRANCO. M.I. \& YAMAMOTO, M. Histopatologia da Medula Óssea na Síndrome Imunodeficiência Adquirida. Rev. Paul. Med., v. 105 , p. 4-11, jan/fev. 1987.

33. OLIVEIRA NETO, N. V. de et al. Transmissão neo-natal por transfusão do vírus HTLV - HI/LAV. Rev. Paul. Med., v. 104, n² 2, p. 111-112, mar/abr. 1986.

34. OLIVIERI, D.P. O Ser Doente. São Paulo: Moraes, 1985.

35. PASTERNAK, F. AIDS-Verdade e mito - História e Fatos São Paulo: Círculo do Livro, 1988, 159p.

36. AMATO NETO, V. Infecção Pós-Transfusional pelo Vírus da Imunodeficiência Humana (HIV) Rev. Paul. Med., v. 106, n 3, p. 115-116, mar/jun. 1988.

37. PEDRO, R. P. de F. et al. "Paracoccidioidomicose e infecção pelo vírus da imunodeficiência humana". Rev. Inst. Med. Trop., São Paulo: v. 23, n 1, p. 119-125, mar/abr. 1989.

38. SCATENA, M.C.M. O mundo do hospital psiquiátrico sob a prespectiva do doente que o habita. São Paulo: Ribeirão Preto, 1991. 
39. SILVA, CM. Desafios da Assistência de Enfermagem: Proposta de soluções na Síndrome da Imunodeficiência Adquirida. In: PRIMEIRO CICLO DE DEBATES SOBRE ASSISTÊNCIA ENFERMAGEM, Anais..., 1988, p.101-106.

40. SPINA FRANCA, O. Patogenia das Infecções do Sistema Nervoso Central e Líquido Cefalorraquidiano - Análise Crítica da Contribuição Diagnóstica". Rev. Paul. Med., v. 107, n 5, p. 169-174, mar/jun 1989.
41. STEINER, G. As idéias de Heidegger. Trad. Álvaro Cabral. São Paulo: Cultrix, 1978.

42. VIEIRA, A.A.B. Assistência de Enfermagem. Enfoque, v. 15, $n^{\circ} 3$, p. 67-70, dez 1987. 